\title{
A Review on Oxidation Kinetics of Carbon Fiber/Carbon Matrix Composites at High Temperature*
}

\author{
By Kazuhiro S. GOTO,** K. H. HAN ${ }^{* *}$ and G. R. St. PIERRE***
}

\section{Synopsis}

The papers on the oxidation kinetics are reviewed to clarify the rate-controlling steps and the micromechanisms of oxidative attack. In the first part of the report, the general oxidation behavior of $c / c$ composites is presented and then the detailed discussion is given on the relation of the oxidation rate to total surface area, to gas flow rate, to partial pressure of oxidizing gases and to the mechanical stresses. Finally, the oxidation rate of $c / c$ composites with antioxidation treatments is discussed.

\section{Introduction}

Carbon matrix composites are widely used in such systems as rocket nozzles, re-entry shields of space vehicles, disk brakes and heating element. However, the unprotected c/c composites have very poor oxidation resistance even at temperatures as low as $500^{\circ} \mathrm{C}$.

In this report, the papers on oxidation kinetics of c/c composites are reviewed to clarify the ratecontrolling steps and the micromechanisms of oxidative attack.

Historically, the oxidation of carbon by $\mathrm{CO}_{2}$ or by $\mathrm{H}_{2} \mathrm{O}$ gas has been studied in relation to "Boudouard's reaction" and the gasification of coal. At moderate temperature, the rate-controlling steps of the following two reaction schemes are known ${ }^{1-7)}$ to be chemical in nature and thus, catalysis is effective for their acceleration.

$$
\begin{gathered}
\mathrm{G}(\mathrm{s})+\mathrm{CO}_{2}(\mathrm{~g})=2 \mathrm{CO}(\mathrm{g}) \\
\mathrm{G}(\mathrm{s})+\mathrm{H}_{2} \mathrm{O}(\mathrm{g})=\mathrm{CO}(\mathrm{g})+\mathrm{H}_{2}(\mathrm{~g})
\end{gathered}
$$

The rates of the chemical reactions increase exponentially with temperature and, eventually above $1200{ }^{\circ} \mathrm{C}$, the rate-controlling step usually changes to the diffusion of gaseous species through the stagnant layer close to the solid carbon. In contrast to the above condition of the reaction, carbon composites are usually used in air and therefore, the reaction would proceed by

$$
\mathrm{C} \text { (fibers or matrix) }+\mathrm{O}_{2}(\mathrm{~g})=\mathrm{CO}_{2}(\mathrm{~g})
$$

The Gibbs energy change of Eq. (3) has a very large negative value and the reaction would proceed always with a big driving force even at very low $\mathrm{O}_{2}$ partial pressures.

The rate of the oxidation would be, therefore, controlled not by the chemical reaction itself but by transport of the gaseous species to and away from the reaction front. The experimental justification for this assumption will be discussed in the following sections.

\section{The General Oxidation Behavior C/C Com- posites}

For many years, S. Kimura and E. Yasuda, and their coworkers have been working on $\mathrm{c} / \mathrm{c}$ composites. As part of their work, the oxidation behavior of the composites has been studied at 650 to $850{ }^{\circ} \mathrm{C} .{ }^{8}$ ) Figure 1 shows the testing assembly they employed. The mixture of nitrogen and air was supplied to the bottom of the reaction chamber and the weight change of the composites was measured by the electrobalance.

Figure 2 shows the relation between the percentage of the burn off (weight loss) and the time for various temperatures. The samples had fiber contents of $67 \%$ and were heat treated at $2800{ }^{\circ} \mathrm{C}$. The rate of oxidation increases with temperature but decreases with time. Yasuda et $a l{ }^{8)}$ have found that the matrix has a faster rate of oxidation and at the initial stage, the matrix is oxidized, followed by a slower

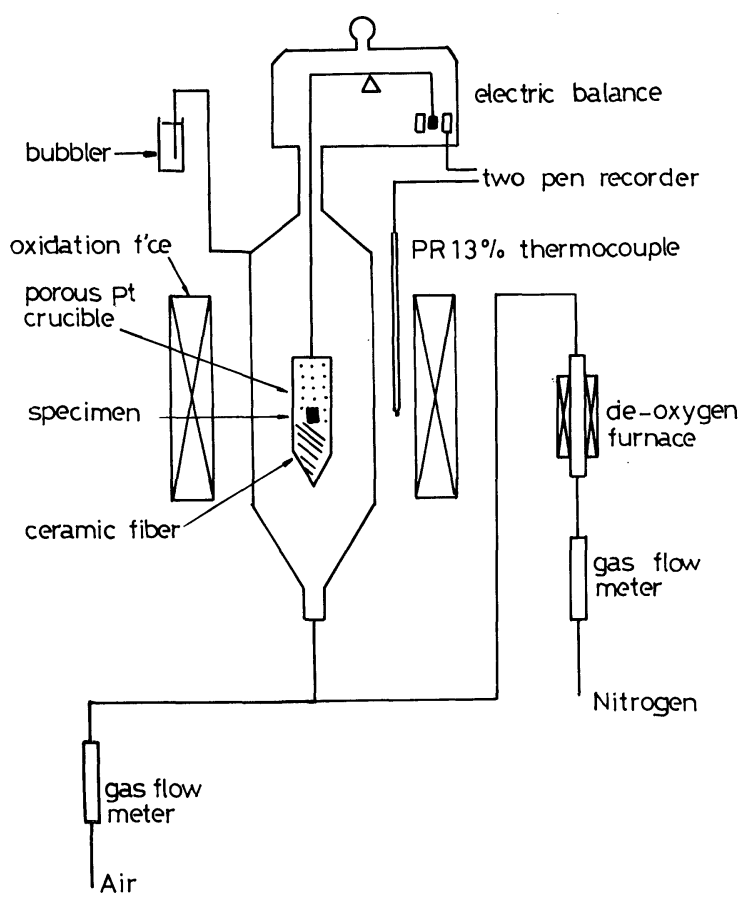

Fig. 1. Testing assembly of oxidation furnace (after Yasuda et al. $\left.{ }^{8)}\right)$.

\footnotetext{
* This paper is one of a series of comprehensive review articles which the editors invite on subjects thought to be timely. Manuscript received on December 18, 1985; accepted in the final form on April 18, 1986. (C) 1986 ISIJ

** Department of Metallurgy, Tokyo Institute of Technology, Ookayama, Meguro-ku, Tokyo 152.

*** Department of Metallurgical Engineering, Ohio State University, Columbus, Ohio 43210-1179, U.S.A.
} 


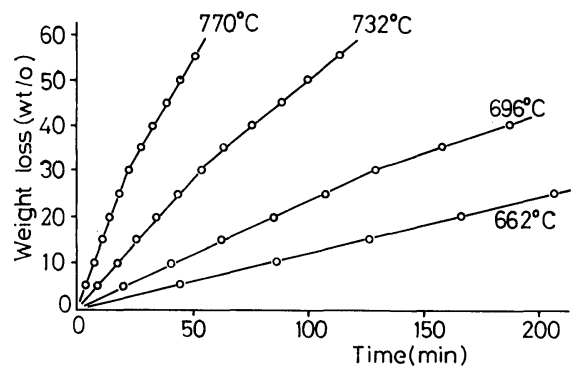

Fig. 2. Oxidation of $\mathrm{c} / \mathrm{c}$ composite (UD-50-28) in air (after Yasuda et al. $\left.{ }^{8)}\right)$.

oxidation of fibers.

Figure 3 shows the effect of heat treatment temperature (HTT) on the oxidation rate. The rate decreases with increase of temperature of heat treatment despite the higher oxidation temperature. This effect of heat treatment has been observed by other investigators. In this figure, the oxidation rate is increasing with time. The rate is defined as slope of the curves in Fig. 3.

Figure 4 shows the relationship between logarithm of the weight loss rate and reciprocal absolute temperature. ${ }^{8)}$ The rate increases with decrease of temperature of heat treatment. Yasuda et al. ${ }^{8)}$ proposed that the rate is controlled by diffusion of oxygen at higher temperature and by chemical reaction at lower temperature. The inflection point moves to higher temperature with the increase of temperature of heat treatment. Qualitatively, their interpretations seem to fit the known facts. The general behavior of the oxidation of the composites is summarized as follows.

The rate of oxidation of carbon fiber/glassy carbon at 650 to $850^{\circ} \mathrm{C}$ is faster than that of pyrolytic graphite or glassy carbon. The oxidation first takes places at the interfaces between fibers and matrix. The reaction, then proceeds to the matrix of graphite region and of the optically anisotropic region and finally to the region of optically isotropic glassy carbon. This indicates that the oxidation is mostly governed by the structural defects or by stress accumulation in the matrix caused by carbonizing shrinkage. The general behavior is that the rate is increased by increase of oxidizing temperature and by decrease of temperature of heat treatment. This general statement seems correct but in details, the relation between the weight loss and time seems more complex.

Figure 5 shows the relation observed by Fischbach and Uptegrove. ${ }^{9)}$ In this figure, G-100 refers to composite with carbonized fiber and matrix, C-500 with graphitized fibers and carbonized matrix, C-700 with graphitized fibers and matrix, and finally, G730 with the same as C-700 but with a different cloth weave. In this figure, the rate accelerates with time. This is a contrast to the results shown in Fig. 2 and similar to the results shown in Fig. 3. They have reported by microscopic observation after various oxidation times that the relative reactivity follows the order: laminar primary binder, glassy impregnant binder, fiber lateral surface, and fiber core. However,

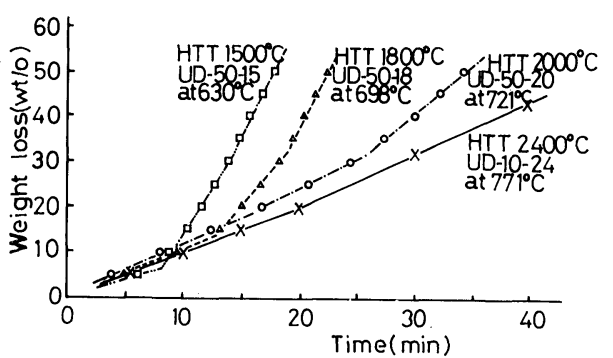

Fig. 3. Oxidation of $\mathrm{c} / \mathrm{c}$ composites with various HTT for oxidation temperatures of $630^{\circ} \mathrm{C}, 721^{\circ} \mathrm{C}$, and 771 ${ }^{\circ} \mathrm{C}$ (after Yasuda et al. ${ }^{8)}$ ).

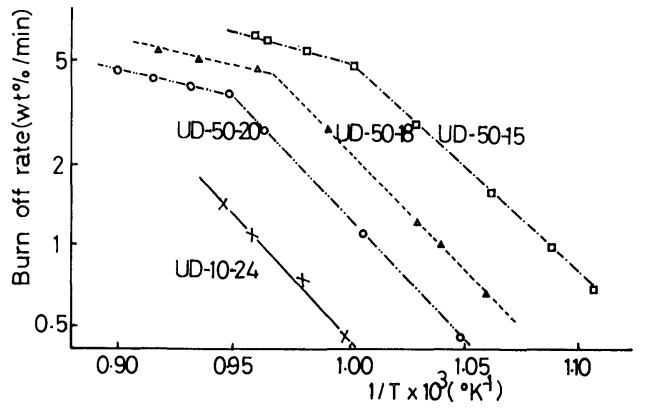

Fig. 4. Arrhenius plots of the oxidation rates for anisotropic region in composites (after Yasuda et $a l{ }^{81}$ ).

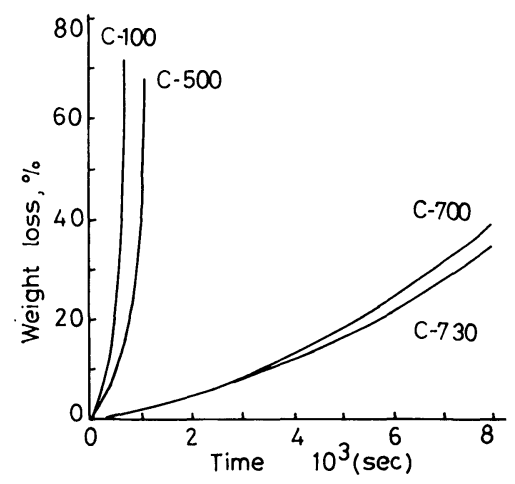

Fig. 5. Isothermal burn off behavior of $\mathrm{c} / \mathrm{c}$ composites in dry air at $650^{\circ} \mathrm{C}$ (after Fischbach and Uptegrove ${ }^{9)}$ ).

the relative reactivity does not always follow the ideal pattern. At high burn off rates, the fibers seem to be more easily oxidized than the matrix. The resistance to oxidation was improved by graphitization, despite the increased fraction of open pores.

\section{Relationship between Oxidation Rate and Total Surface Area of Reaction}

Some investigators believe that the rate of oxidation of the composites by air is controlled by the reaction itself at lower temperatures and by gaseous transport at higher temperatures. However, the critical temperature to separate the two controlling steps is not well defined nor exactly determined. Two difficult problems remain; firstly, the reaction surface itself changes with time, and secondly, open pores and micro cracks are generated during oxidation. The former problem makes it very difficult 
to express the chemical reaction rate as a simple function of time, temperature and macroscopic surface area of the composite. The latter problem makes it difficult to express the rate of the transport of the gaseous species as a simple function of the initial porosity and the labyrinth factor of the composites. For example, Table 1 shows the increase of the surface area of the carbon derived from phenolic resin, which was measured by Chang and Rhee. ${ }^{10)}$ This table tells us that the surface area markedly increases after $5 \%$ oxidation. The rate of the increase is very much larger for carbon heat-treated at lower temperatures.

Figure 6 shows the relation between the weight loss and oxidation time for various temperatures. Figure 7 shows the relation between logarithm rate and reciprocal absolute temperature. The rate of oxidation

Table 1. Effect of oxidation on surface area. $\left(\mathrm{m}^{2} / \mathrm{g}\right)$

\begin{tabular}{c|rcc}
\hline \multirow{2}{*}{ HTT $\left({ }^{\circ} \mathbf{C}\right)$} & \multicolumn{3}{|c}{ Oxidation (weight loss) } \\
\cline { 2 - 4 } & $0 \%$ & $5 \%$ & $10 \%$ \\
\hline 1000 & 12.6 & 599 & 854 \\
1400 & 1.3 & 107 & 114 \\
1800 & 2.1 & 24.3 & 20.5 \\
2400 & 2.4 & 4.6 & 3.1 \\
\hline
\end{tabular}

(after Chang and Rhee ${ }^{10)}$ )

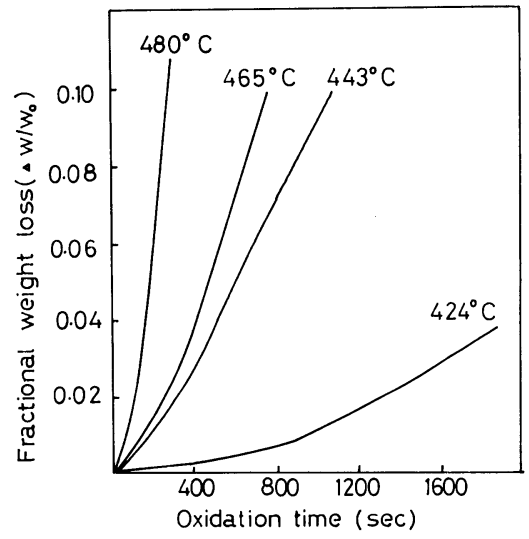

Fig. 6. Oxidation of carbon heat-treated at $1000{ }^{\circ} \mathrm{C}$ for $1 \mathrm{~h}$ (after Chang and Rhee $\left.{ }^{101}\right)$.

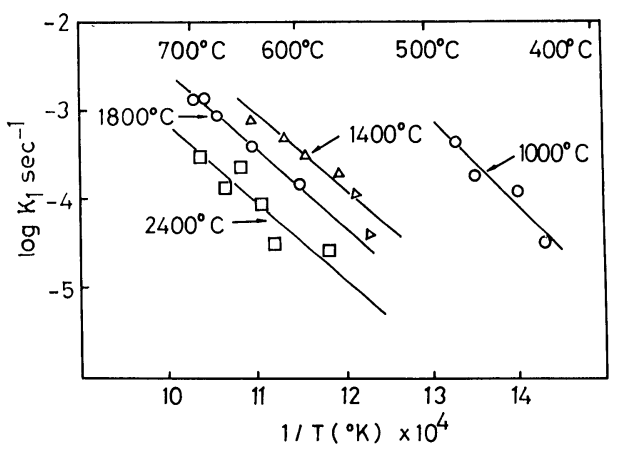

Fig. 7. Oxidation rates $v s$. temperature for carbon samples heat-treated at different temperatures (after Chang and Rhee $\left.{ }^{10 \prime}\right)$. increases with increase of temperature of oxidation and with increase of time. The rate, as seen in Fig. 7 , increases by decrease of the temperature of the heat treatment of the carbon. The increase of the oxidation rate by decrease of temperature of the heat treatment is interpreted by the increased amount of retained impurities. ${ }^{10)}$ Therefore, it seems effective to take off impurities in the $\mathrm{c} / \mathrm{c}$ composites by special procedures. The method of taking off impurities is very specific for different kinds of impurities. For example, impurities of alkaline elements and alkaline earth elements would be vaporized off as vapors of halides, when halogen elements are reacted with the c/c composites. However, this kind of treatment should be made very carefully avoiding any negative effects on the microstructure of the composites. In general, the true reason of the effect of temperature of heat treatment of $\mathrm{c} / \mathrm{c}$ composites has not been well clarified yet.

Table 2 shows the increase of the surface area by

Table 2. Surface area changed with oxidation. (oxidation temperature $650^{\circ} \mathrm{C}$ )

\begin{tabular}{c|ccc}
\hline \multirow{2}{*}{$\begin{array}{c}\text { Oxidation } \\
\text { level } \\
(\mathrm{wt} \%)\end{array}$} & \multicolumn{3}{|c}{ Surface area $\left(\mathrm{m}^{2} / \mathrm{g}\right)$} \\
\cline { 2 - 4 } & $\mathrm{A}^{*}$ & $\mathrm{~B}^{*}$ & $\mathrm{C}^{*}$ \\
\hline 0 & 23.0 & 21.6 & 13.9 \\
5 & 198.0 & 33.8 & 12.7 \\
10 & 229.0 & 35.8 & 12.4 \\
\hline
\end{tabular}

* Samples A, B, and C are different in condition of preparation of $\mathrm{c} / \mathrm{c}$ composites (after Chang and Runsnak ${ }^{11)}$ ).

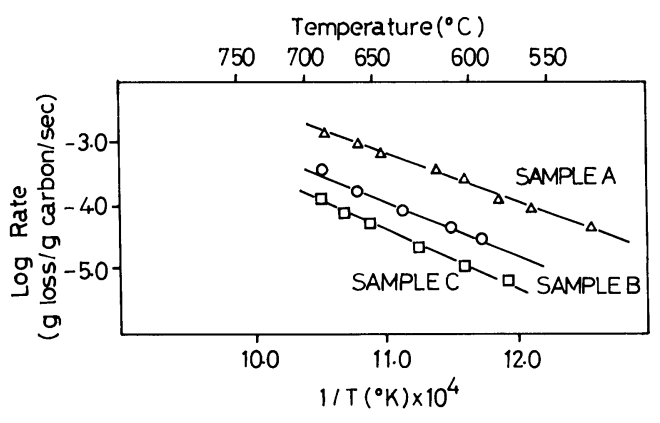

Fig. 8. Temperature dependence of oxidation rates for ground composites (after Chang and Runsnak ${ }^{11)}$ ).

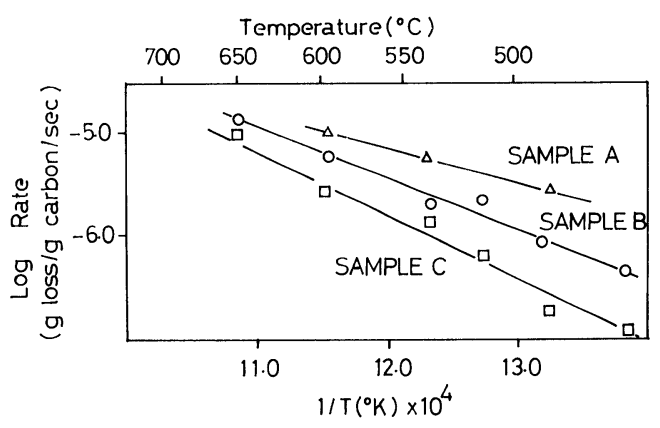

Fig. 9. Temperature dependence of oxidation rates for bulk composites (after Chang and Runsnak ${ }^{11}$ ). 
the oxidation of c/c composite made of $40 \%$ carbon binder, $40 \%$ high strength carbon fibers and $20 \%$ carbon filler, designed for use for aircraft brakes, which has been reported by Chang and Runsnak. ${ }^{11)}$

Figures 8 and 9 show the relation between logarithm rate and reciprocal absolute temperature, for ground and bulk composites, respectively. The rate is faster for the ground samples than the bulk. The difference among samples $\mathrm{A}, \mathrm{B}$, and $\mathrm{G}$ with different preparation conditions would be expected from the differences in the surface area determined by BET method. Because the rate is influenced by the extent of graphitization, porosity, active sites and impurity level, it is not easy to drive a simple relationship between the rate and surface area. However, in general the rate is large, when the surface area determined by BET method is large as long as other factors remain constant. However, it would be questionable that the area determined by the BET method is proportional to the number of active sites for the oxidation of carbon at high temperature.

\section{Relationship between Oxidation Rate and Gas Flow Rate}

When the gas flow rate is increased, the thickness of the stagnant layer close to the solid phase is decreased. Chang and Runsnak ${ }^{11}$ ) have presented interesting experimental results on the effect of the gas flow rate, as shown in Table 3 . At $650{ }^{\circ} \mathrm{C}$, the effect of the flow rate is very slight even with a large increase in the flow rate. However, at $750{ }^{\circ} \mathrm{C}$, the rate is very much increased by the increase of the flow rate. Therefore, they concluded that the rate controlling step is the chemical reaction below $650^{\circ} \mathrm{C}$ and the diffusion of gaseous species above $750^{\circ} \mathrm{C}$.

When the rate increases with the increase of flow rate, diffusion control is generally assumed. However, the phenomenon might be more complicated. Figures 10 and 11 show experimental results by Thrower and Marx. ${ }^{12)}$ The oxidation rate of graphite is increased by increase of partial pressure of $\mathrm{CO}_{2}$ or $\mathrm{H}_{2} \mathrm{O}$ in helium at $893{ }^{\circ} \mathrm{C}$. If one examines both figures carefully, it can be noted that the rate is increased by increase of the flow rate from 9.2 to 13.8 but then decreased by further increase to $15.3 \mathrm{~cm}^{3} /$ sec. The surface roughness might be changed by the change of the flow rate. Therefore, it is not a general conclusion that the rate is controlled by the reaction itself below $650{ }^{\circ} \mathrm{C}$ and by diffusion above $750^{\circ} \mathrm{C}$. More careful experiments are necessary to establish the general rule on the rate-controlling steps of oxidation of $\mathrm{c} / \mathrm{c}$ composites.

\section{Relationship between Oxidation Rate and Partial Pressures of Oxidizing Gases}

The rate of the oxidation of carbon would be nearly proportional to the partial pressure of oxidizing gases for both diffusion and chemical reaction controlled cases. The diffusion rate is proportional to the difference in concentration of oxidizing gas divided by the length of diffusion path. The chemical reaction usually increases in proportion to the concentra-

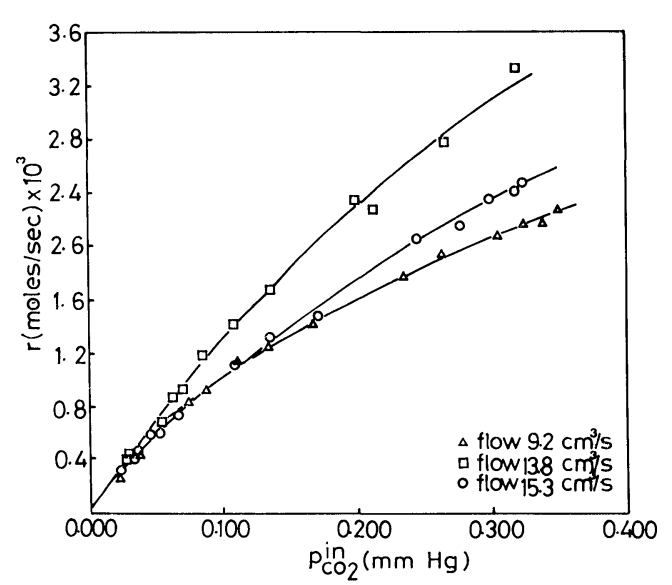

Fig. 10. Reaction rate of Stackpole 2020 graphite $v s$. partial pressure of $\mathrm{CO}_{2}$ in the inlet gas at $893^{\circ} \mathrm{C}$ for different flow rates (after Thrower and $\operatorname{Marx}^{12)}$ ).

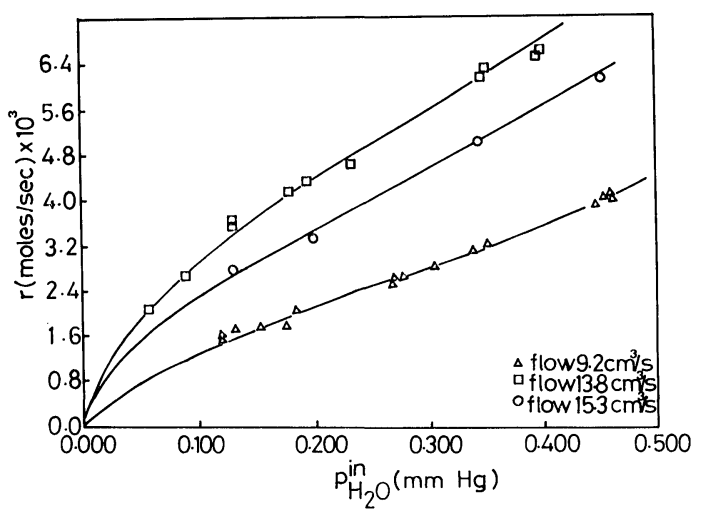

Fig. 11. Reaction rate of Stackpole 2020 graphite $v s$. partial pressure of $\mathrm{H}_{2} \mathrm{O}$ in the inlet gas at $893{ }^{\circ} \mathrm{C}$ for different flow rates (after Thrower and $\left.\mathrm{Mark}^{12}\right)$ ).

Table 3. Influence of oxidation rates on gas flow rates (bulk composites).

\begin{tabular}{|c|c|c|c|c|c|}
\hline \multirow{2}{*}{$\begin{array}{c}\text { Flow rate } \\
(\mathrm{cc} / \mathrm{min})\end{array}$} & \multirow{2}{*}{$\left(\frac{\text { flow }}{100}\right)^{1 / 2}$} & \multicolumn{2}{|c|}{$650^{\circ} \mathrm{C}$} & \multicolumn{2}{|c|}{$750^{\circ} \mathrm{C}$} \\
\hline & & $\frac{\% \text { wt. loss }}{\min }$ & $\frac{\% w t . \text { loss }}{0.11}$ & $\frac{\% \mathrm{wt} \cdot \operatorname{loss}}{\min }$ & $\frac{\% w t . ~ l o s s}{0.29}$ \\
\hline 100 & 1.00 & 0.11 & 1.0 & 0.29 & 1.0 \\
\hline 500 & 2.24 & 0.13 & 1.2 & 0.71 & 2.4 \\
\hline 1000 & 3.16 & 0.15 & 1.4 & 0.97 & 3.3 \\
\hline 1500 & 3.87 & 0.16 & 1.5 & 1.03 & 3.6 \\
\hline
\end{tabular}

(after Chang and Runsnak ${ }^{11)}$ ) 
tion of the reactants. Figures 10 and 11 satisfy the preceding anticipation. The rate seems nearly proportional to the partial pressures of $\mathrm{CO}_{2}$ and $\mathrm{H}_{2} \mathrm{O}$ at $893{ }^{\circ} \mathrm{G}$.

\section{Relationship between Oxidation Rate and Mechanical Stresses}

Thrower and Marx have measured the effect of compressive stress upon the rate of oxidation of Stackpole 2020 graphite. ${ }^{12)}$ Table 4 shows their experimental results. From this table, one can find no major effect of the compressive stress upon the oxidation of graphite under their experimental condition.

When graphite is under tensile stress, oxidation is accelerated by increase of open pores and microcracks. This effect has been experimentally proved by Krefeld and his coworkers. ${ }^{13,14)}$ According to their observation, the rate of oxidation of graphite increased by the tensile stress in a gaseous atmosphere of argon with small additions of water vapor.

Figure 12, reported by Peng, ${ }^{15)}$ shows the relation between tensile strength and temperature after $20 \mathrm{~min}$ oxidation of polycrystalline graphite. The tensile strength has been measured under two different gas supplies at various temperatures. Figure 13 also shows the relation between the tensile strength and oxygen flow rate during a $20 \mathrm{~min}$ oxidation of two different kinds of carbon. ${ }^{15}$ ) The decrease in the tensile strength shown in Figs. 12 and 13 was interpreted by Peng $^{15)}$ as an indication that pore enlargement and component debonding is responsible for the decrease of the ultimate tensile strength at higher temperature. Figure 14 shows the relation between compressive strength and weight loss of graphite

Table 4. Effect of compressive stress upon the rate of oxidation of graphite in $\mathrm{He}-\mathrm{CO}_{2}$ and $\mathrm{He}-$ $\mathrm{H}_{2} \mathrm{O}$ mixtures (after Thrower and $\mathrm{Mark}^{12)}$ ).

\begin{tabular}{|c|c|c|c|c|c|}
\hline $\begin{array}{c}\text { Sample } \\
\text { temp. } \\
\left({ }^{\circ} \mathrm{C}\right)\end{array}$ & $\begin{array}{c}\text { Comp. } \\
\text { stress } \\
\text { (psi) }\end{array}$ & $\begin{array}{c}X_{\mathrm{CO}_{2}}^{\mathrm{in}} \\
(\mathrm{ppm})\end{array}$ & $\begin{array}{c}X_{\mathrm{H}_{2} \mathrm{O}}^{\mathrm{in}} \\
(\mathrm{ppm})\end{array}$ & $\begin{array}{c}X_{\mathrm{CO}}^{\text {out }} \\
(\mathrm{ppm})\end{array}$ & $\begin{array}{c}X_{\mathrm{Co}}^{\mathrm{out}} \\
(\mathrm{ppm})\end{array}$ \\
\hline \multirow{3}{*}{888} & 0 & 85 & - & 60 & 45 \\
\hline & 267 & 85 & - & 60 & 45 \\
\hline & 362 & 85 & - & 60 & 45 \\
\hline \multirow{3}{*}{888} & 0 & 175 & - & 135 & 80 \\
\hline & 267 & 175 & - & 135 & 80 \\
\hline & 362 & 175 & - & 135 & 80 \\
\hline \multirow{4}{*}{893} & 0 & - & 885 & 75 & 125 \\
\hline & 267 & - & 885 & 75 & 125 \\
\hline & 362 & - & 885 & 75 & 125 \\
\hline & 456 & - & 885 & 75 & 125 \\
\hline \multirow{3}{*}{908} & 0 & 115 & - & 85 & 60 \\
\hline & 456 & 115 & $\ldots$ & 85 & 60 \\
\hline & 650 & 115 & - & 85 & 60 \\
\hline \multirow{3}{*}{908} & 0 & - & 125 & 15 & 30 \\
\hline & 362 & - & 125 & 15 & 30 \\
\hline & 456 & - & 125 & 15 & 30 \\
\hline
\end{tabular}

oxidized at 600,700 , and $800{ }^{\circ} \mathrm{C}$, reported by Thrower and Bognet. ${ }^{16)}$

\section{Oxidation Rates of C/C Composites with Anti-oxidation Treatments}

Super alloys for turbine blades are usually protected from oxidation at high temperature by dense layers of $\mathrm{Al}_{2} \mathrm{O}_{3}, \mathrm{SiO}_{2}$ or $\mathrm{Cr}_{2} \mathrm{O}_{3}$. Therefore, it is convenient to apply the same principle to the protection of $\mathrm{c} / \mathrm{c}$

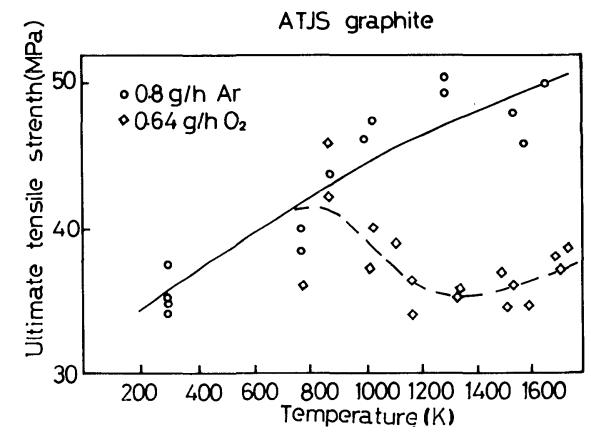

Fig. 12. Relation between ultimate tensile strength and temperature after $20 \mathrm{~min}$ oxidation of graphite (after Peng15) .

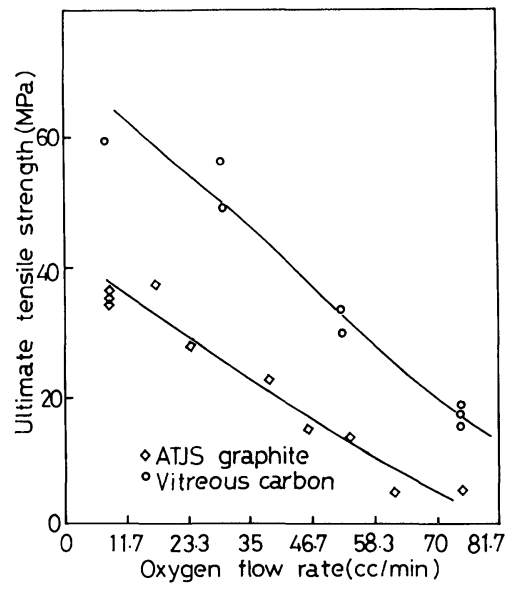

Fig. 13. Effect of oxygen flow rate on ultimate tensile strength of graphite and vitrous carbon during 20 min oxidation (after Peng ${ }^{15)}$ ).

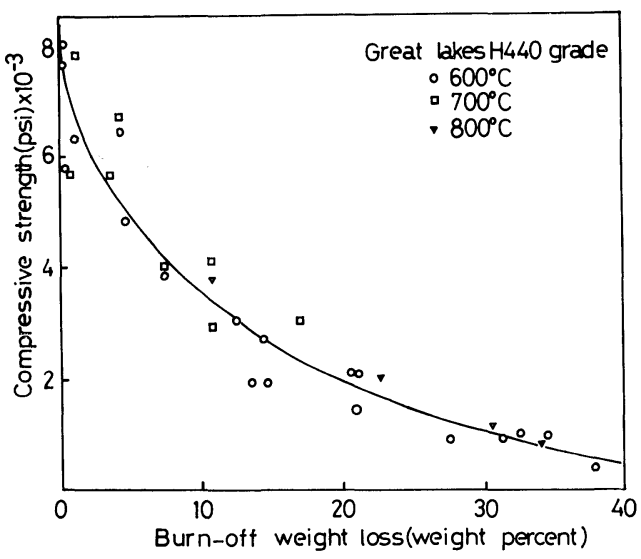

Fig. 14. Relation between compressive strength and weight loss of graphite oxidized at various temperature (after Thrower and Bognet ${ }^{16)}$ ). 


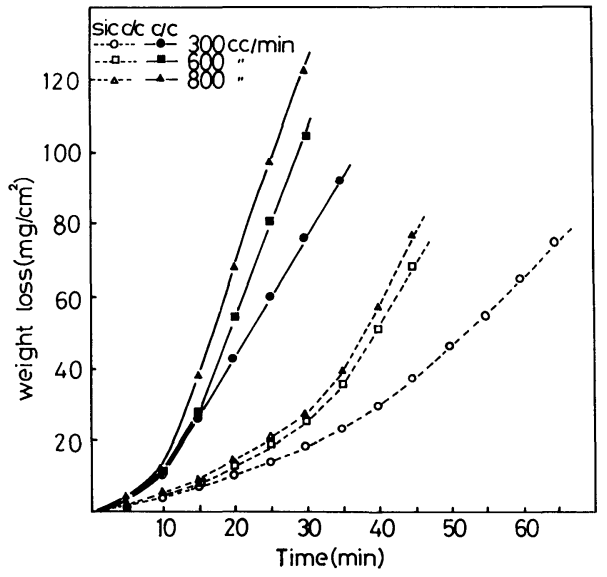

Fig. 15. Comparison of the oxidation rates of $\mathrm{SiC}$ added $\mathrm{c} / \mathrm{c}$ and $\mathrm{c} / \mathrm{c}$ and effect of flow rate of air on the oxidation at $600{ }^{\circ} \mathrm{C}$ (after Han et al. $\left.{ }^{17)}\right)$.

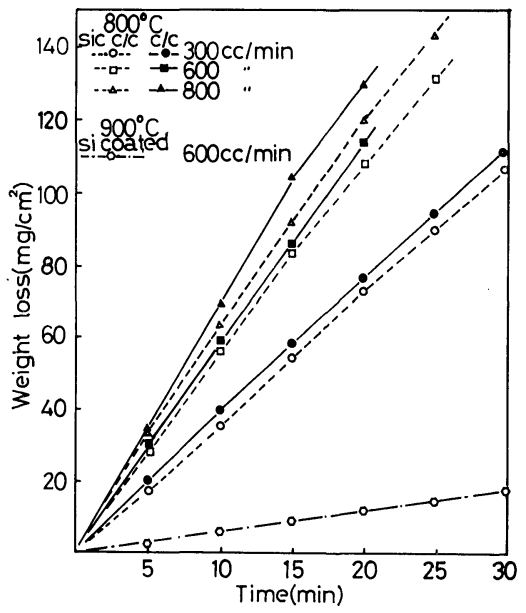

Fig. 16. Oxidation of $\mathrm{SiC}$ treated $\mathrm{c} / \mathrm{c}, \mathrm{c} / \mathrm{c}$, and $\mathrm{Si}$ coated $\mathrm{c} / \mathrm{c}$ and effect of flow rate of air on the oxidation rates at 800 and $900{ }^{\circ} \mathrm{C}$ (after Han et al. ${ }^{17)}$ ).

composites.

Figure 15 shows the decrease of oxidation rate of c/c composites which have $\mathrm{SiC}$ incorporated in the matrix. ${ }^{17)}$ However, this treatment is not effective at $800{ }^{\circ} \mathrm{C}$, as shown by Fig. 16.17) Also, this figure shows that the composite immersed in liquid silicon at $1500{ }^{\circ} \mathrm{C}$ is oxidized very slowly in comparison with other composites. Naslain, Hagenmuller, Christin, Heraud and Choury have developed a method to protect composites. Their process ${ }^{18)}$ includes a vacuum vapor impregnation using organosilane, $\mathrm{CH}_{3} \mathrm{SiCl}_{3}$ with hydrogen under reduced pressure. Also, Naslain, Rossignol, Hagenmuller, Christin, Heraud and Choury ${ }^{19)}$ have devised a related process using $\mathrm{TiCl}_{4}, \mathrm{CH}_{4}$ and $\mathrm{H}_{2}$ under reduced pressure. It is important to use reduced pressure, because the gas mixture can more easily penetrate the pores of the composites. Figure 17 shows the weight change of the composites with a $\mathrm{TiC}$ treatment at $1500{ }^{\circ} \mathrm{C}$ in natural convection of air. The weight change is very small at $1500{ }^{\circ} \mathrm{C}$. The oxidation rate is decreased with increased content of TiC. Figure 18(a) shows the relation between weight change and

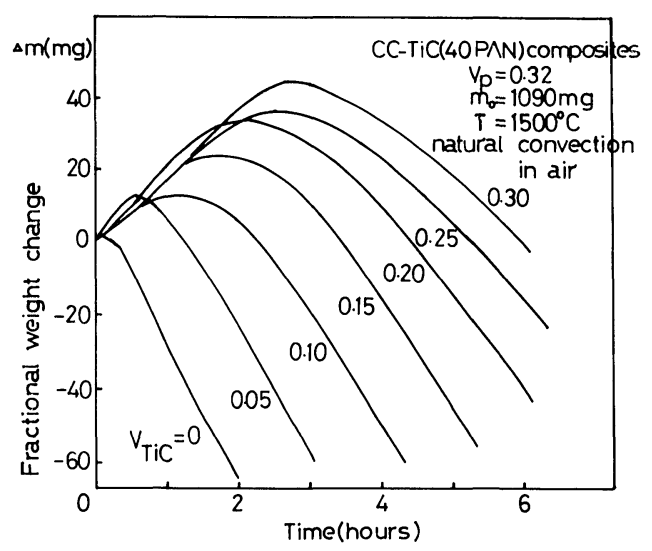

Fig. 17. Oxidation kinetics in air of 2D-G-G/TiC composites (PAN-based fibers) at different contents of TiC $\left(V_{\text {TiC }}\right)$ (after Naslain et al. $\left.{ }^{19 \prime}\right)$.

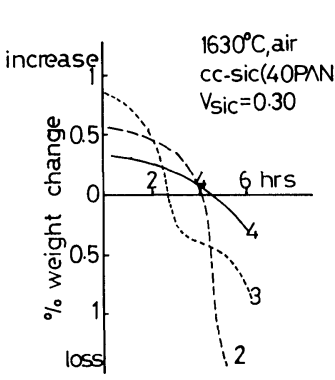

(a)

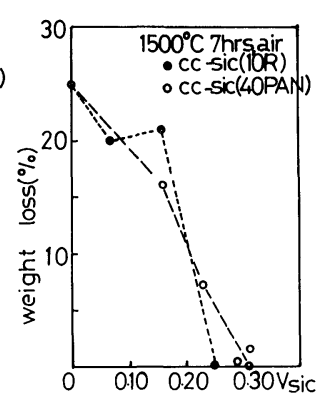

(b)
Fig. 18. Air oxidation tests on $2 \mathrm{D}-\mathrm{C}-\mathrm{C} / \mathrm{SiC}$ composites;

(a) oxidation kinetics at $1630^{\circ} \mathrm{C}$

(b) influence of $V_{\mathrm{SiC}}$ (and of related residual porosity) on the weight loss at $1500{ }^{\circ} \mathrm{C}$ (after Naslain et al. $^{\left.{ }^{19}\right)}$ ).

time (hours), when three different $\mathrm{c} / \mathrm{c}$ composites containing $\mathrm{SiC}$ are oxidized at $1630^{\circ} \mathrm{C}$ in air. In Fig. 18 (a), the weight of the sample increases during the initial stage of oxidation due to the oxidation of $\mathrm{SiC}$ to $\mathrm{SiO}_{2}$ even evolution off of $\mathrm{CO}$ gas. Figure 18(b) shows the relation between the weight loss and content of $\mathrm{SiC}$, when the composites with $\mathrm{SiC}$ are oxidized for $7 \mathrm{~h}$ at $1500{ }^{\circ} \mathrm{C}$. The work of Naslain et al. ${ }^{18,19)}$ demonstrate clearly that the layers of $\mathrm{SiO}_{2}$ or $\mathrm{TiO}_{2}$ are protective for $\mathrm{c} / \mathrm{c}$ composites under some conditions. However, at much higher temperatures, these oxide layers are not thermodynamically stable in contact with solid carbon and carbides. This kind of problem will be discussed in the future.

\section{Future Works and Concluding Remarks}

References of 20) to 24) provide a useful recent supplement to the earlier experimental works on oxidation of carbon materials and composites. The present report is limited in scope to and the effects of microstructure of carbon fibers upon oxidation rate have not been discussed. However, the origin of the fibers, their heat treatment, distribution of the diameters, mode of weaving and other factors all have some effects upon the rate of the oxidation of the composites. Nevertheless, the present review clearly 
identifies some future problems, which should be rigorously attached. These may be listed as follows:

(1) More physicochemical studies should be made on coating procedures of carbon fibers themselves as well as the woven and processed composites. Unique applications of processes such as PVD and CVD must be studied.

(2) A very wide range of coating materials and options must be studied in addition to $\mathrm{SiO}_{2}, \mathrm{Al}_{2} \mathrm{O}_{3}$ and $\mathrm{TiO}_{2}$.

(3) The deterioration of the protective layers may proceed in many ways, e.g., by solid state reactions with carbon matrix and carbides and by the attack of external gases and thermal stresses. The micromechanisms of the deterioration of the protective coatings should be clarified to suggest new protective coating systems.

(4) The deterioration of the coatings may be accelerated by adhesion of harmful molten salts and aggressive dusts, such as powders of $\mathrm{Na}_{2} \mathrm{CO}_{3}, \mathrm{NaOH}$, and $\mathrm{B}_{2} \mathrm{O}_{3}$.

Such oxides mixed with transition metal oxides would be very harmful to the usual acidic protective oxide coatings.

(5) As already discussed, oxidation causes serious damage to the microstructures of the composites. Thus, mechanical properties are very much weakened. It is very important to use reliable anti-oxidation treatments, but on the other hand, it is also very important to improve the mechanical reliability of the composites. Fundamental studies of these problems are needed to complement and enhance the current materials development and demonstration efforts.

\section{REFERENCES}

1) H. S. Taylor and H. A. Neville: "Catalysis in the Interaction of Carbon with Steam and with Carbon Dioxide", J. Amer. Chem. Soc., (1921), 2055-2071.

2) D. W. Mckee and D. Chatterji: “ The Catalytic Behaviour of Alkali Metal Carbonates and Oxides in Graphite Oxidation Reactions ", Carbon, 13 (1975), 381-390.

3) B. P. Jalan and Y. K. Rao: "A Study of the Rates of Catalyzed Boudouard Reaction ", Carbon, 16 (1978), 175184.

4) Y. K. Rao and B. P. Jalan: "A Study of the Rates of Carbon-Carbon Dioxide Reaction in the Temperature Range 839 to $1050^{\circ} \mathrm{C}$ ", Met. Trans., 3 (1972), 2465-2477.

5) D. A. Fox and A. H. White: "Effects of Sodium Carbonate upon Gasification of Carbon and Production of Producer Gas ", Ind. Eng. Chem., 23 (1931), 259-266.

6) W. Y. Wen: "Mechanisms of Alkali Metal Catalysis in the Gasification of Coal. Ghar. or Graphite", Catal. Rev. Sci. Eng., 22 (1) (1980), 1-28.
7) Y. K. Rao: "Catalysis in Extractive Metallurgy", J. Metals, (1983), July, 46-50.

8) E. Yasuda, S. Kimura and Y. Shibusa: "Oxidation Behaviour of Carbon Fiber/Glassy Carbon Composite ", Trans. JSCM, 6 (1980), No. 1, 14-23.

9) D. B. Fischbach and D. R. Uptegrove: "Oxidation Behaviour of Some Carbon/Carbon Composites ", Ext. Abst. 13th Biennial Conf. on Carbon, (1977), 130-131.

10) H. W. Chang and S. K. Rhee: "Oxidation of Carbon Derived from Phenolic Resin ", Carbon, 16 (1978), 17-20.

11) H. W. Chang and R. M. Rusnak: "Oxidation Behaviour of Carbon/Carbon Composites ", Carbon, 17 (1979), 407410.

12) P. A. Thrower and D. R. Marx: "The Oxidation of Graphite under Compressive Stress ", Ext. Abst. 13th Biennial Conf. on Carbon, (1977), 41-42.

13) R. Krefeld, G. Linkenheil, Ph. Glaude and W. Karcher: Carbon '72, Barden-Baden, (1972), 216.

14) R. Krefeld, G. Linkenheil and W. Karcher: ORNLCONF-730601, (1973), 88.

15) T. C. Peng: "Effects of Oxidation on the Mechanical Properties of Carbon/Graphite", Ext. Abst. 13th Biennial Conf. on Carbon, (1977), 263-264.

16) P. A. Thrower and J. C. Bognet: "The Effect of Oxidation on the Compressive Strength of Graphite ", Ext. Abst. 13th Biennial Conf. on Carbon, (1977), 265-266.

17) K. H. Han, K. S. Goto, G. R. St. Pierre, H. Ono and K. Nagata: Tetsu-lo-Hagané, 72 (1986), S713.

18) R. Naslain, P. Hagenmuller, F. Christin, L. Heraud and J.J. Choury: "The Garbon Fiber/Carbon and Silicon Carbide Binary Matrix Composites, A New Class of Materials for High Temperature Applications", Advances in Composite Materials, Vol. 2, ICCM3. 3rd Inter. Conf. on Composite Materials, ed. by A. R. Bunsell et al., Pergamon Press, Paris, (1980).

19) R. Naslain, J. Y. Rossignol, P. Hagenmuller, F. Christin, L. Heraud and J. J. Choury: "Synthesis and Properties of New Composite Materials for High Temperature Applications Based on Carbon Fibers and C-SiC or C-TiC Hybrid Matrices ", Rev. Chimie Minerale, 18 (1981), 544-564.

20) S. Kimura, E. Yasuda and Y. Tanabe: "Oxidation and Sublimation of Carbon/Carbon Composite", A Report in U.S.-Japan Joint Meeting on Carbon Materials, 1984, Washington, D.C.

21) S. Kimura and E. Yasuda: "On Carbon/Carbon Composites ", A Memorial Lecture of 50 Years Aniversary of Research Institute of Industrial Materials, Tokyo Institute of Technology, March 1985, Tokyo.

22) P. Ehrburger, C. Bourgeois and J. Layaye: "Characterization of c/c Composites by Oxidation in Air ", Abstracts of 3rd Inter. Carbon Conf., (1980), 647-650.

23) P. A. Thrower and J. G. Bognet: "The Effect of Oxidation on the Compressive Strength of Graphite", Ext. Abst. 13th Biennial Conf. on Carbon, (1977), 265-650.

24) H. W. Chang and R. M. Runsnak: "Oxidation Mechanisms of Carbon-Carbon Composites ", Ext. Abst. 13th Biennial Conf. on Carbon, (1977), 449-450. 